\title{
Tehranolide inhibits cell proliferation via calmodulin inhibition, PDE, and PKA activation
}

\author{
Shokoofe Noori • Zuhair M. Hassan
}

Received: 24 April 2013 / Accepted: 18 July 2013 /Published online: 13 November 2013

(C) The Author(s) 2013. This article is published with open access at Springerlink.com

\begin{abstract}
Tehranolide, natural sesquiterpene lactone with an endoperoxide group, has been shown to inhibit cell growth in cancer cells. Tehranolide was purified from Artemisia diffusa . To detect cell viability and proliferation, MTT assay was performed. In order to determine the role of tehranolide on calmodulin $(\mathrm{CaM})$ structure and activity, its effects were evaluated with fluorescence emission spectra and CaM-mediated activation of phosphodiesterase (PDE1), in comparison with artemisinin. In fact, PDE1 inhibition, cAMP accumulation, and cAMP-dependent protein kinase A (PKA) activation were examined. The inhibitory effect of tehranolide on CaM structure is more than artemisinin. The kinetic analysis of tehranolide-CaM interaction has shown that this agent competitively inhibited the activation of PDE1 without affecting Vmax. Tehranolide increased $\mathrm{Km}$ value in higher amounts compared with artemisinin. Moreover, tehranolide had a cytotoxic effect on K562 cell line but not on normal human lymphocytes. Additionally, PDE inhibition and consequent cAMP accumulation and PKA activity were required for inhibiting cancer cell growth by tehranolide. Our results show that tehranolide significantly reduces cell proliferation in a time and dose-dependent manner in K562 cells via CaM inhibition, following PDE inhibition, cAMP accumulation, and consequent PKA activity.
\end{abstract}

Keywords Tehranolide $\cdot$ Calmodulin $\cdot$ Phosphodiesterase · cAMP · PKA

S. Noori $(\bowtie)$

Department of Biochemistry, Faculty of Medicine,

Shahid Beheshti University of Medical Sciences, Tehran, Iran

e-mail: shnoori85@yahoo.com

\section{Z. M. Hassan}

Department of Immunology, School of Medical Sciences,

Tarbiat Modares University, Tehran, Iran

\begin{abstract}
Abbreviations
CaM Calmodulin

PDE Phosphodiesterase

cAMP Cyclic AMP

PKA cAMP-dependent protein kinase A
\end{abstract}

\section{Introduction}

Cell proliferation is regulated by a complex array of signaling pathways. cAMP acts as an important second messenger in many pathways regulating cell growth, differentiation, and apoptosis [1]. The elevation of cAMP subsequently activates cAMP-dependent PKA that can phosphorylate various proteins, thus regulating a cascade of transcriptional events implicated in the inhibition of cancer cell growth [2-4]. PDEs degrade cAMP and promote the return of PKA to its inactive tetrameric state [5]. PDE is an isozymic family composed of many different types, grouped into seven broad gene families including $\mathrm{Ca}^{2+} \mathrm{CaM}$-dependent (PDE1) [6].

PDE inhibitor-induced apoptosis is selective towards malignant cells without affecting normal cells [7]. CaM has been shown to play roles in regulating apoptosis [8]. CaM antagonists induce apoptosis in various tumor models. Thus, $\mathrm{CaM}$ is involved in the regulation of biological processes such as cell proliferation [9] and has been extensively used as anticancer agents, but the molecular mechanism of $\mathrm{CaM}$ antagonistmediated apoptosis is poorly understood $[3,10]$.

Artemisinin (Fig. 1), a natural sesquiterpene lactone with an endoperoxide group, has been extracted from Artemisia апnиа. Artemisinin has effective antitumor activities [11-15]. Tehranolide (Fig. 1) is classified as sesquiterpene lactone with an endoperoxide group which is purified from Artemisia diffusa [16]. It was previously demonstrated that artemisinin and DHA have inhibitory effects on CaM and PDE1 activity 
Fig. 1 a Chemical structures of artemisinin and tehranolide. $\mathbf{b}$

${ }^{13} \mathrm{C}$ NMR spectroscopy of tehranolide

a

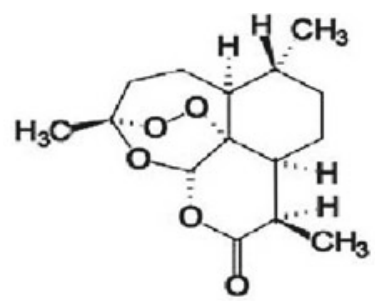

Artemisinin

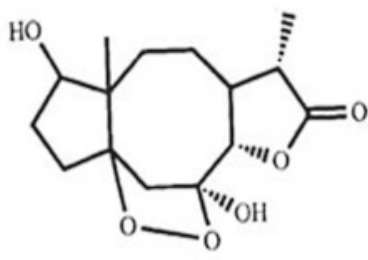

Tehranolide

b

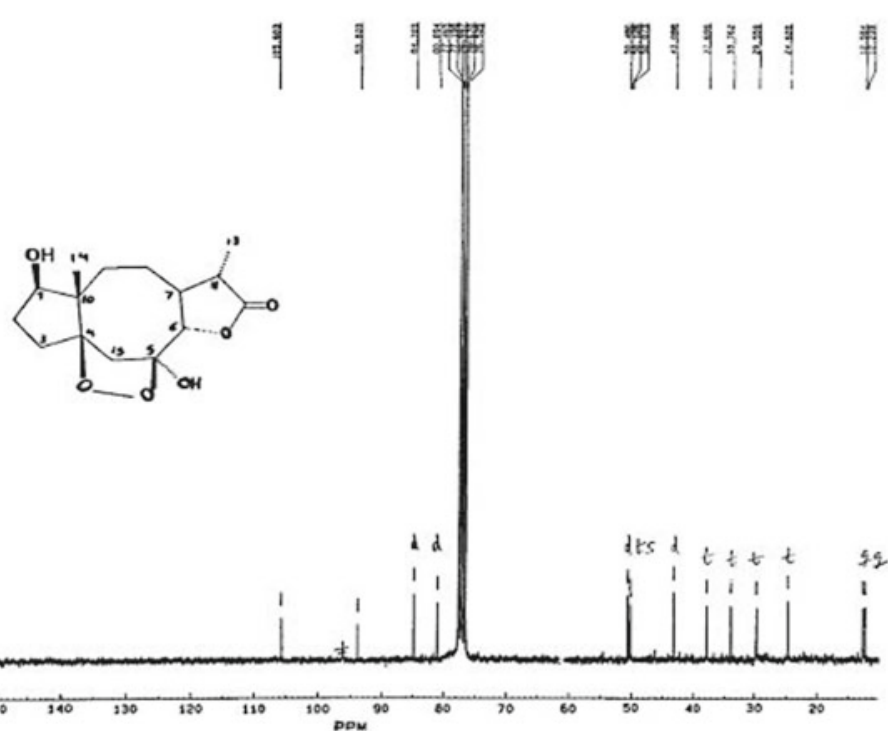

[17-19]. It was reported that tehranolide possessed antitumor activities, and it arrested cells in the G1 phase [20-22]. In the present study, the effects of tehranolide on CaM, PDE1, and the cAMP/PKA signaling pathway to define the mechanism of cell growth inhibition were investigated.

\section{Materials and methods}

Isolation and purification of tehranolide

One thousand grams of $A$. diffusa were collected from East of Iran. Dry plant was extracted by a mixture of n-hexane/ethyl acetate/methanol (1:1:1) and kept in room temperature for $24 \mathrm{~h}$. The extract was passed through Wattman filter paper. The filtrate was evaporated by vacuum rotary evaporator at $45^{\circ} \mathrm{C}$ for $2 \mathrm{~h}$ and kept in freezer. The concentrated filtrate was run through a silica gel column chromatography at different solvent polarities starting from a nonpolar solvent (n-hexane) to a medium polarity (n-hexane/ethyl acetate) and ended with ethyl acetate alone. Then, mixtures of different concentrations of n-hexane/ethyl acetate/methanol with increasing concentration of methanol towards the higher polarity were used.
Fractions were collected from these processes, and the purity of the components in each fraction was evaluated by thin layer chromatography (TLC). Fractions 35, 36, 37, 38, 39, 40, 41, and 42 exhibited a single band on TLC. Afterwards, tehranolide was identified by the $125 \mathrm{MHz}{ }^{13} \mathrm{C}$ NMR spectra, using $\mathrm{CDCl}_{3}$ as a solvent.

\section{Spectrofluorophotometer}

Fluorometric measurements were carried out using a Shimadzu Model RF-5000 spectrofluorometer. The instrument was operated in the energy mode, and the emission spectrum of $\mathrm{CaM}$ was studied at $\lambda \mathrm{ex}=277 \mathrm{~nm}$ and $\lambda \mathrm{em}=$ $310 \mathrm{~nm}$. Tehranolide and artemisinin had no fluorescence activity at these wavelengths.

\section{Assay for PDE-1 activity}

A modification of a three-step PDE1 assay was used to determine CaM-dependent activation of PDE1 and its inhibition by tehranolide. 3,5-cyclic-nucleotide PDE, 2-mM cyclic AMP, and $100 \mu \mathrm{M} \mathrm{CaM}$ in $0.5 \mathrm{ml}$ of Tris buffer solution $(40 \mathrm{mM}$ Tris-chloride, $0.1 \mathrm{mM} \mathrm{MnCl}_{2}$, and $0.01 \mathrm{mM} \mathrm{CaCl}_{2}$ in a glass 
of distilled water at $\mathrm{pH} 7.5$ ) were incubated alone, with increasing concentrations of native tehranolide $\left(1 \times 10^{-6}\right.$ to $9 \times 10^{-6} \mathrm{M}$ ) for $10 \mathrm{~min}$ at $30^{\circ} \mathrm{C}$. The reaction was stopped by placing the test tubes in a boiling water bath for $2 \mathrm{~min}$ and then cooling. The 5-AMP in the reaction product was cleaved into adenosine and inorganic phosphate by incubation with 5'nucleotidase $(100 \mu \mathrm{l})$ for $10 \mathrm{~min}$. The reaction was stopped by adding $0.05 \mathrm{ml}$ of trichloride acid (55\%, weight to volume) and $0.15 \mathrm{ml}$ molybdic acid solution and centrifuged until clear. The clear supernatants were decanted into the test tubes with Fiske-Subbarow reagent. Blue color reaction was allowed to develop in the presence of inorganic phosphorus for $10 \mathrm{~min}$. Absorbance at $660 \mathrm{~nm}$ was measured with spectrophotometry.

\section{Determination of the kinetic parameters}

$\Delta \mathrm{G}\left(\mathrm{H}_{2} \mathrm{O}\right)$, the best parameter for the estimation of macromolecule stability, was determined for CaM in the presence of tehranolide and artemisinin. The difference between the free energy of the native and denatured forms of CaM $(\Delta G)$ was calculated using [23] the following equation:

$$
\begin{aligned}
& \Delta \mathrm{G}=-\mathrm{RT} \quad \operatorname{Ln}[\mathrm{Fd} /(1-\mathrm{Fd})] \\
& \mathrm{F}_{\mathrm{d}}=\left(\mathrm{Y}_{\mathrm{n}}-\mathrm{Y}_{\text {obs }}\right) /\left(\mathrm{Y}_{\mathrm{n}}-\mathrm{Y}_{\mathrm{d}}\right) \\
& \operatorname{Ln}\left[\left(\mathrm{Y}_{\mathrm{n}}-\mathrm{Y}_{\text {obs }}\right) /\left(\mathrm{Y}_{\mathrm{obs}}-\mathrm{Y}_{\mathrm{d}}\right)\right]=-\mathrm{RTLnK}
\end{aligned}
$$

Where $\mathrm{R}$ is the gas constant, $\mathrm{T}$ is the absolute temperature, $\mathrm{Y}_{\mathrm{obs}}$ is the observed fluorescence emission intensity of CaM at each concentration of artemisinin, and tehranolide $Y_{n}$ and $Y_{d}$ are the values for the native and denatured states, respectively.

The plot of $\Delta \mathrm{G}$ changes against tehranolide and artemisinin concentrations showed a linear behavior with the following equation [23]:

$\Delta \mathrm{G}=\Delta \mathrm{G}\left(\mathrm{H}_{2} \mathrm{O}\right)-\mathrm{m}[\mathrm{D}]$

Where $\Delta \mathrm{G}\left(\mathrm{H}_{2} \mathrm{O}\right)$ is the value of $\Delta \mathrm{G}$ at zero concentration of ligand, $m$ is a measure for the dependence of $\Delta G$ on ligand concentration, and $[\mathrm{D}]$ is the concentration of ligand.

A kinetic analysis of the inhibition of CaM-dependent PDE by tehranolide and artemisinin resulted in Lineweaver-Burk plots. $\mathrm{Km}$ values were calculated in the absence and presence of inhibitors from Lineweaver-Burk plots of data. The point at which the lines crossed the $y$-axis represents the theoretical maximum velocity (Vmax) of the activated PDE1 in the presence and absence of inhibitors.

\section{Cell culture}

The human erythroleukemic cell line (K562) was purchased from Pasteur Institute, Tehran, Iran. In this study, the cells were cultured in RPMI 1640 medium (Gibco/BRL) supplemented with $10 \% \mathrm{FBS}$ (GIBCO/BRL), 100 unit/ml penicillin/100 mg/ $\mathrm{ml}$ streptomycin, and $1 \%$ L-glutamine (Gibco/BRL). The cells were grown in a humidified atmosphere containing $5 \% \mathrm{CO}_{2}$ at $37{ }^{\circ} \mathrm{C}$. Normal lymphocytes were collected from healthy persons. Human peripheral blood was obtained from healthy volunteers (aged 25-50 years). Blood samples were obtained by venipuncture of the vein, and blood was collected in sterile EDTA K3-containing tubes.

PBMCs were obtained by centrifugation over $1.077 \mathrm{~g} / \mathrm{ml}$ Ficoll-Hypaque gradient (Sigma, UK).

Cells were washed in saline and finally resuspended in RPMI 1640 medium and cultured $\left(5 \times 10^{4}\right.$ cells $\left./ \mathrm{ml}\right)$ in 96well flat-bottom culture plates in medium supplemented with different doses of tehranolide, $10 \%$ fetal calf serum, $2 \mathrm{~mm} \mathrm{~L}$ glutamine, $100 \mathrm{U} / \mathrm{ml}$ penicillin, and $100 \mu \mathrm{g} / \mathrm{ml}$ streptomycin (Sigma-Aldrich), and the cell viability analysis was measured.

Cell viability analysis

Analysis of cell viability was performed with MTT (3-[4, 5methylthiazol-2-yl]-2, 5-diphenyl-tetrazolium bromide) assay. Briefly, growing cells were cultured (5,000 cells/well) overnight in 96-well tissue culture plates. Different doses of tehranolide were added to the respective wells, after 24,48 , and $72 \mathrm{~h}, 20 \mu \mathrm{L}$ MTT (Sigma-Aldrich, USA) was directly added to the media with a final concentration of $2 \mathrm{mg} / \mathrm{ml}$. After 4-h incubation, the medium containing MTT was discarded, and $100 \mu \mathrm{L}$ DMSO (Sigma-Aldrich, USA) was added. MTT crystals were completely solubilized with libration for $10 \mathrm{~min}$. Absorbance was measured in an ELISA reader at $570 \mathrm{~nm}$, and viability was expressed as the percentage of untreated controls.

\section{Quantitative determination of cAMP concentration}

The intracellular cAMP content was determined using cAMP enzyme immunoassay kit (Stratagene, La Jolla, CA). Briefly, a total of $2 \times 10^{5}$ cells were washed with phosphate-buffered saline (PBS) and harvested with centrifugation. Cell pellets were resuspended in lysis reagent provided by the kit. The lysed cells were immediately assayed for cAMP according to the manufacturer's protocol. The assay was based on competition between unlabeled cAMP and a fixed quantity of peroxidase-labeled cAMP for a limited number of binding sites on a cAMP-specific antibody.

\section{Measurement of PKA activity}

PKA activity was measured using the colorimetric PKA assay kit. The treated cells were washed with ice-cold PBS twice, 
resuspended in lysis buffer (50 mM Tris- $\mathrm{HCl}, 2.5 \mathrm{mM}$ EDTA, $1 \mathrm{mM} \mathrm{MgCl} 2,10 \mathrm{mM} \mathrm{NaF}, 10 \%$ glycerol, $\mathrm{pH}$ 7.2), sonicated, and centrifuged. Supernatants were taken as lysates. Thirty micrograms of cell lysate was used to measure PKA activity. PKA activity assays were performed following the manufacturer's instructions included with the colorimetric PKA assay kit.

\section{Blocking PKA activation on cell growth inhibition}

Rp-cAMP (Adenosine 3,5-cyclic monophosphorothioate triethyammonium salt hydrate), a specific inhibitor of cAMP-dependent protein kinase A (Biolog Life Science Institute, Bremen, Germany), was purchased from Sigma and diluted in supplemented RPMI to the required concentrations. Cells were preincubated with Rp-cAMP for $20 \mathrm{~min}$ before treatment with tehranolide.

\section{Statistical analysis}

At first, normality of the data and homogeneity of variances were tested with $\mathrm{K}-\mathrm{S}$ and Levene's statistical tests, respectively. Then, one-way analysis of variance or Mann-Whitney nonparametric test was used to determine the statistical significance $(p<0.05)$ between values of test and control groups. Data were analyzed using SPSS software version 16 , and results were expressed as the mean \pm standard error (mean $\pm \mathrm{SE}$ ).

\section{Results}

Tehranolide structure

The purified material was characterized by ${ }^{13} \mathrm{C}$ NMR spectroscopy. The structure of tehranolide has been shown in Fig. 1.

Interaction of tehranolide with calmodulin

The inhibitory effect of the drug on CaM structure was determined by fluorescence emission spectra; the change of fluorescence emission spectra of $\mathrm{CaM}$ indicated the interaction of ligand with $\mathrm{CaM}$, representing the drug-induced conformational changes of $\mathrm{CaM}$. These results were shown an increase in maximum emission of $\mathrm{CaM}$, which was induced by both tehranolide and artemisinin (Fig. 2a).

Inhibition of CaM-dependent cAMP PDE-1 by tehranolide

An increased concentration of tehranolide was tested based on the measurement of enzyme activity. The method involved the
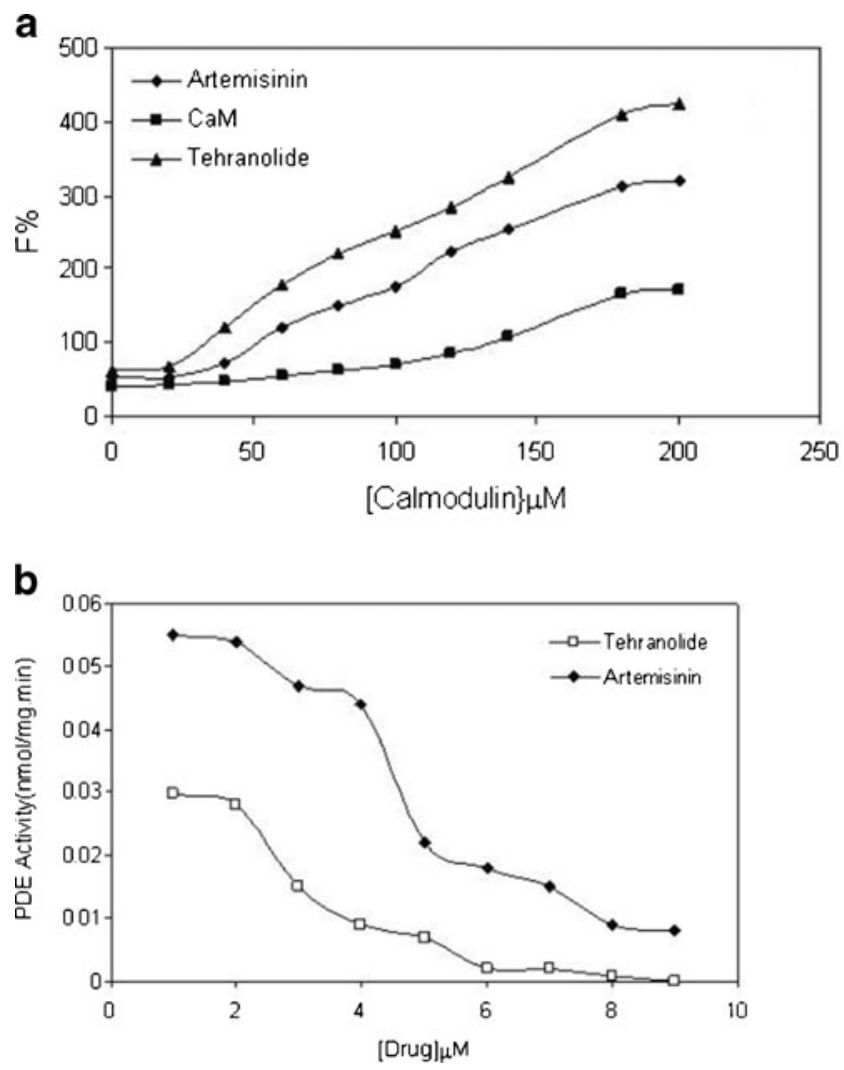

Fig. 2 a The fluorescence spectra of calmodulin at $0.043 \mathrm{mg} / \mathrm{ml}$ concentration in $40 \mathrm{mM}$ Tris- $\mathrm{HCl}$ buffer, $\mathrm{pH} 7.4$ at $25^{\circ} \mathrm{C}$. The increment in the fluorescence emission of calmodulin by increasing its concentration in the free form and in the presence of $10^{-5} \mathrm{M}$ of artemisinin or $10^{-5} \mathrm{M}$ of tehranolide. b Calmodulin-dependent PDE1 activity versus the concentrations of artemisinin and tehranolide

hydrolysis of cAMP to AMP that was quantified with the spectrophotometer method. PDE1 activity was plotted against the concentrations of tehranolide (Fig. 2b).

Kinetic analysis of PDE1 activity and inhibition of PDE1 by tehranolide

The kinetic constant of PDE1was determined. Km value of PDE1 in the absence of inhibitor was $0.05 \pm 0.001 \mu \mathrm{M}$; whereas in the presence of tehranolide and artemisinin, it was 0.1 and $0.5 \mu \mathrm{M}$, respectively, suggesting that in the presence of tehranolide and artemisinin, the $\mathrm{Km}$ values increased in a concentration-dependent manner. The results indicated that tehranolide and artemisinin increased the $\mathrm{Km}$ value without affecting Vmax of the reaction. The Lineweaver-Burk plots demonstrated that both agents were competitive inhibitors of PDE1 (Fig. 3a). The effectiveness of the inhibitors is normally expressed by the constant, $\mathrm{Ki}$, which is the reciprocal of the enzyme-inhibitor affinity. In addition, Ki values were determined using a Dixon plot (Fig. 3b). The 


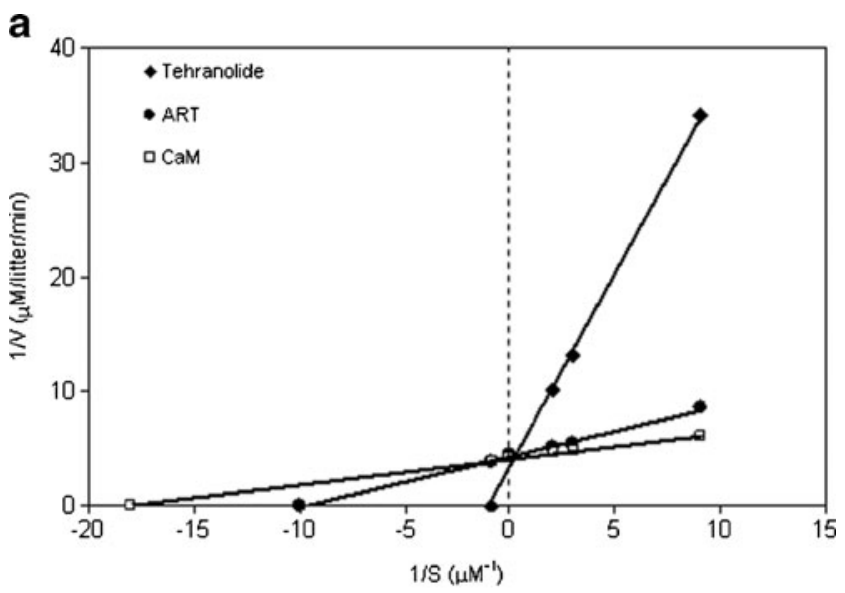

b

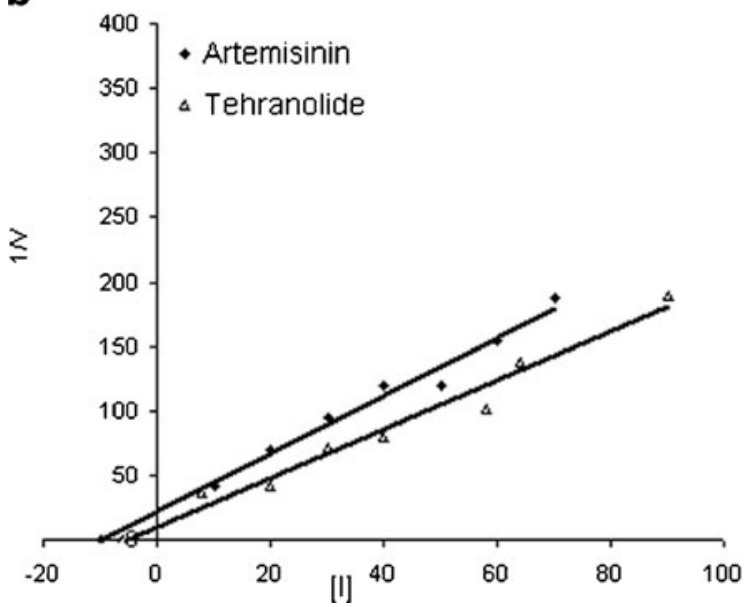

Fig. 3 a Kinetic analysis of the PDE1 activity and the mode of inhibitory action of both compounds was examined using the Lineweaver-Burk plot method. Inhibition was performed with $5 \mu \mathrm{M}$ tehranolide and $5 \mu \mathrm{M}$ artemisinin in varying concentrations of cAMP (calmodulin concentration in all the reactions was constant, $100 \mu \mathrm{M})$. b Dixon plots: Inhibition was performed with varying concentrations of artemisinin and tehranolide

$\mathrm{Ki}$ constants for tehranolide and artemisinin were 6.1 and $10 \mu \mathrm{M}$, respectively.

The effect of tehranolide on calmodulin stability

The procedure was performed for $\mathrm{CaM}$ in the presence of tehranolide and artemisinin, separately. The $\Delta \mathrm{G}$ changes for the complexes of $\mathrm{CaM}$ with tehranolide and artemisinin were shown in Fig. 4. The estimated $\Delta \mathrm{G}\left(\mathrm{H}_{2} \mathrm{O}\right)$ from the linear curves in the presence of tehranolide was $2.13 \mathrm{kcal} \mathrm{mol}^{-1}$, while this value was $4.16 \mathrm{k} \mathrm{cal} \mathrm{mol}^{-1}$ in the presence of artemisinin (Table 1).

\section{Measurement of cell growth}

To measure the effect of tehranolide on growth of tumor cells, different doses of tehranolide were tested; the results indicated

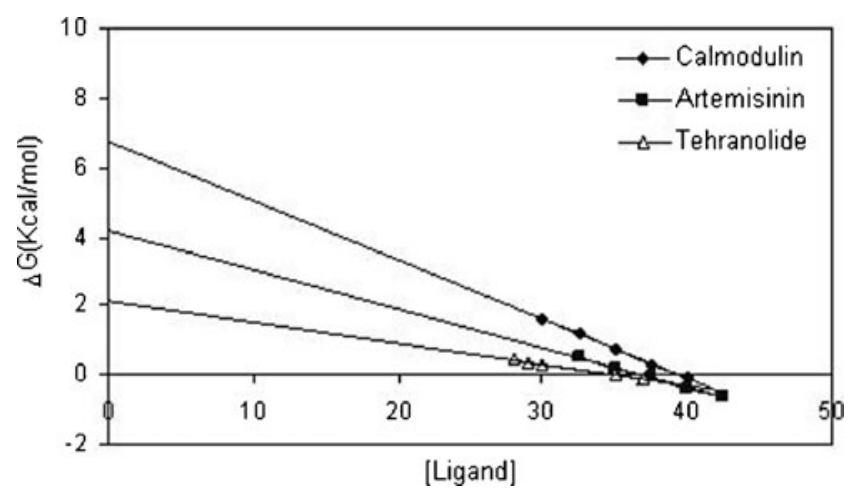

Fig. 4 The changes of free energy $(\Delta G)$ versus the varying concentrations of tehranolide and artemisinin $(\mu \mathrm{M})$

that tehranolide reduced the growth of K562 cell line in a concentration-dependent manner.

MTT assay indicated that tehranolide had no cytotoxic effects on the growth of peripheral blood lymphocytes, but it was effective in growth inhibition of K562 cell line (Fig. 5a).

The effect of tehranolide on intracellular levels of cAMP and PKA activity in K562 cells

To determine the level of cAMP accumulation and PKA activity in the K562 cells in response to tehranolide, cAMP content and PKA activity were measured using enzyme immunoassay. In response to tehranolide and artemisinin (PDE1 inhibitors), intracellular cAMP accumulation were observed in K562 cells (Fig. 5b, c). Additionally, tehranolide-treated group showed a significant increase in PKA activity comparing with control group (Fig. 5d).

Activation of PKA by cAMP is required for tehranolide-induced cell growth inhibition

To confirm that the effect of tehranolide on cell growth inhibition was mediated by PDE inhibition and the consequent increase of cAMP and PKA activation, cells were preincubated for 20 min with specific inhibitor of PKA (Rp-cAMP) $(10 \mu \mathrm{M})$ and then treated with tehranolide $(35-75 \mu \mathrm{M})$; afterwards, MTT assay was performed.

Table 1 Calculated parameters of calmodulin stability against artemisinin and tehranolide

\begin{tabular}{llllll}
\hline Ligand & $\begin{array}{l}\text { Concentration } \\
(\mu \mathrm{M})\end{array}$ & $\begin{array}{l}\Delta \mathrm{G}\left(\mathrm{H}_{2} \mathrm{O}\right) \\
(\mathrm{kCal} / \mathrm{mol})\end{array}$ & $\begin{array}{l}\mathrm{m}(\mathrm{kCal} / \\
\mathrm{mol} / \mu \mathrm{M})\end{array}$ & $\begin{array}{l}\mathrm{D}_{1 / 2} \\
(\mu \mathrm{M})\end{array}$ & $\mathrm{R}^{2}$ \\
\hline Calmodulin & 5 & 6.7 & 0.1611 & 39.66 & 0.99 \\
Artemisinin & 5 & 4.16 & 0.1179 & 36.81 & 0.99 \\
Tehranolide & 5 & 2.13 & 0.088 & 30.34 & 0.99 \\
\hline
\end{tabular}


a

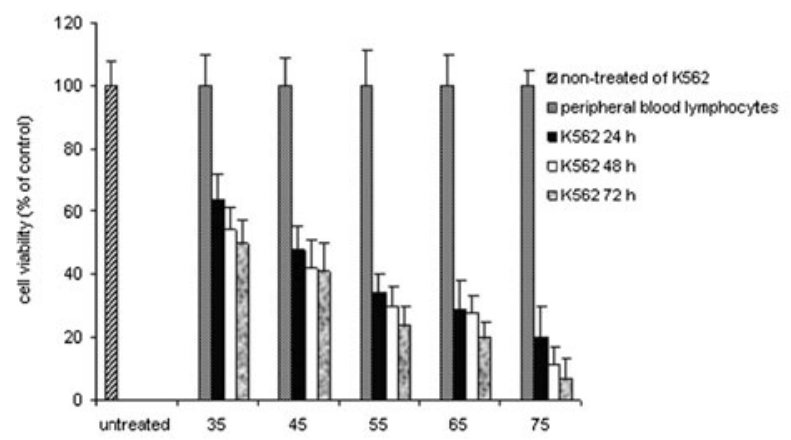

C
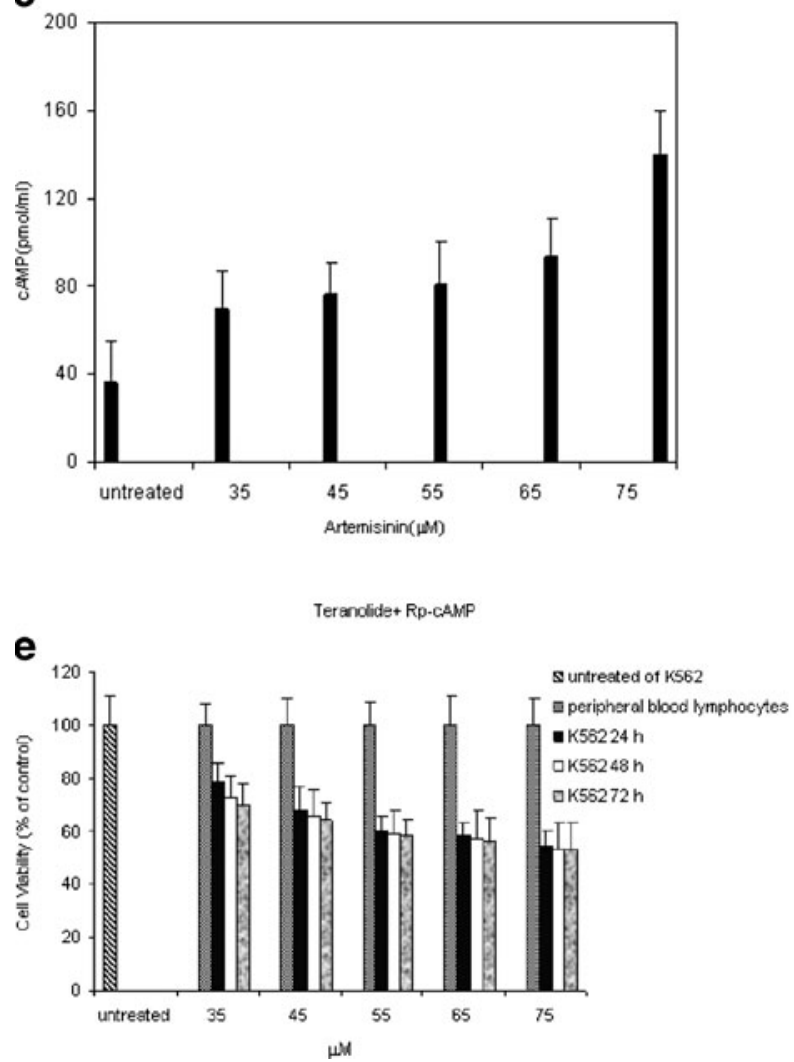

b

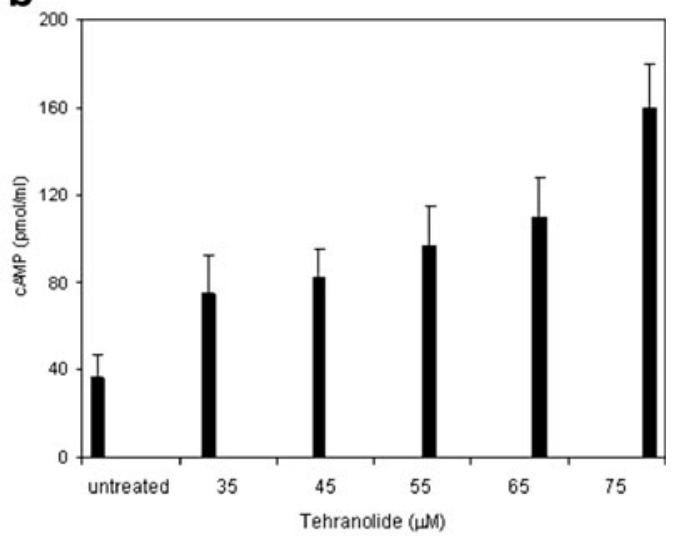

d

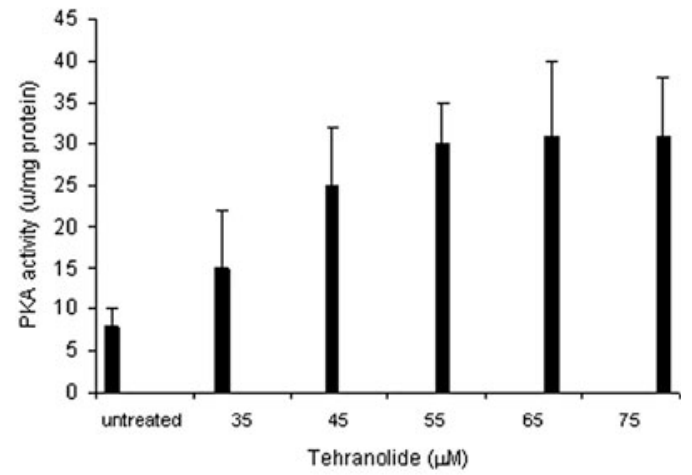

Fig. 5 a Cytotoxicity effect of tehranolide against of K562 cell line. Cells were incubated with increasing concentrations $(35-75 \mu \mathrm{M})$ of tehranolide for 24,48 , and $72 \mathrm{~h}$ Cell viability was quantified by applying the MTT assay. Bars represent the mean \pm SEM of three independent experiments performed in triplicate, $p<0.05$ represents significant differences compared to control values, whereby control was set as $100 \%$. b Intracellular levels of cAMP in tehranolide-treated K562 cells. K562 cells were treated with varying concentrations of tehranolide followed by analysis of intracellular cAMP levels. c Intracellular levels of cAMP in artemisinin-treated K562 cells. d PKA activity in tehranolide-treated

\section{Discussion}

$\mathrm{CaM}, \mathrm{a} \mathrm{Ca}^{2+}$-dependent regulatory protein, has been shown to overexpress in malignant and transformed cells [24, 25],
K562 cells. PKA activity was determined using the Pierce colorimetric assay kit that utilizes a fluorescent-labeled kempeptide (a PKA-specific peptide (LRRASLG) substrate). e RpcAMP, a specific inhibitor of cAMP-dependent protein kinase A, inhibits PKA activation induced by cAMP. To detect the role of PKA activity on cell proliferation, cells were pretreated with $\operatorname{RpcAMP}(10 \mu \mathrm{M})$ for $20 \mathrm{~min}$ and then treated with different concentrations of tehranolide and harvested at 24,48 , and $72 \mathrm{~h}$. Significant differences $(p<0.05)$ were found compared with untreated cells. The results are representative of three separate experiments

resulting in alterations in the interaction of $\mathrm{CaM}$ with its target proteins [3]. Furthermore, $\mathrm{CaM}$ antagonists have been shown to inhibit tumor cell invasion in vitro [26]. Moreover, PDE inhibitors induce apoptosis in malignant cells, without affecting 
normal cells [27]. PDE inhibitors are also currently available or in development for treatment of a variety of other pathological conditions. In the recent years, it has been shown that artemisinin and its derivatives have anticancer effects [28-30].

According to the previous results, our team follows up the research in two steps: In the first step, tehranolide was purified from $A$. diffusa, its effect on CaM structure was investigated by spectrofluorometry. Our findings indicated that tehranolide induced some conformational changes on the CaM and increased fluorescence emission of CaM; the inhibitory effect of tehranolide was higher than artemisinin, as shown in Fig. 2a.

Subsequently, the effects of CaM activation on PDE1 in the absence (control) and presence of artemisinin or tehranolide were studied, and the kinetic analysis of PDE1 activity was performed. It was demonstrated that tehranolide is a more potent inhibitor of PDE1 activity than artemisinin (Fig. 2b). The plot of CaM-dependent PDE activity versus tehranolide and artemisinin concentrations (Fig. 2b) demonstrated that tehranolide and artemisinin could both inhibit the CaM-dependent activity of PDE1. However, tehranolide acted more potent than artemisinin. It was found that tehranolide has a higher $\mathrm{Ki}$ constant $(6.1 \mu \mathrm{M})$ compared with artemisinin $(10 \mu \mathrm{M})$, as shown in Fig. $3 \mathrm{a}$.

On the other hand, tehranolide and artemisinin could act synergistically and increase the Km value of PDE1, while Vmax was constant in the presence or absence of both compounds. The data confirmed that these agents competitively inhibited the activation of PDE1 without affecting Vmax. This parameter was used to estimate CaM stability after the complex formation with artemisinin or tehranolide.

As shown in Fig. 4, the calculated $\Delta \mathrm{G}\left(\mathrm{H}_{2} \mathrm{O}\right)$ values are in agreement with our abovementioned findings. The decrease in $\Delta \mathrm{G}\left(\mathrm{H}_{2} \mathrm{O}\right)$ value is the main reason for the decrease in protein stability because of its interaction with the mentioned ligands. However, the level of decrease in $\Delta \mathrm{G}\left(\mathrm{H}_{2} \mathrm{O}\right)$ value appeared to be in the order of tehranolide $>$ artemisinin, and this means that tehranolide induces more instability in CaM structure, indicated by lower $\Delta \mathrm{G}\left(\mathrm{H}_{2} \mathrm{O}\right)$.

In addition, the concentration required for tehranolide to interact with $\mathrm{CaM}$ is lower than artemisinin, suggesting that tehranolide has higher affinity for interaction with CaM, which is related to its structure. This interpretation has been confirmed with the higher m-value which is a measure of protein sensitivity to ligand [21], and the lower $\mathrm{D}_{1 / 2}$, which is the ligand concentration that induces instability in half of the protein molecules (Table. 1).

In the second step, the cytotoxic activity of tehranolide was investigated. It was found that tehranolide inhibited growth of K562 cells, while it had no cytotoxic effect on the growth of peripheral blood lymphocytes, as shown in Fig. 5a. In an attempt to elucidate the role of raised levels of cAMP and PKA activity in cell growth inhibition by tehranolide and artemisinin, the intracellular cAMP content by enzyme immunoassay were measured, as shown in Fig. 5b, c.
It is hypothesized that cell growth inhibition by tehranolide is via a PKA-mediated mechanism.

To test this hypothesis, the effect of tehranolide on PKA activity was evaluated. Our results have shown that tehranolide leads to increased activity of PKA, as shown in Fig. 5d.

Finally, to address whether PKA plays a role in the cytotoxic activity of tehranolide, cells have been pretreated with a specific PKA inhibitor (Rp-cAMP) in the presence of different concentration of tehranolide and the cytotoxicity indicated by MTT assay, as shown in Fig. 5e. As a conclusion, treatment of cells with tehranolide in the presence of pRp-cAMP strongly decreases the inhibitory effects of tehranolide in K562 cells.

Through this study and based upon our pervious results, it was confirmed that tehranolide, as a potent CaM antagonist, causes an increase in the cAMP concentration following PDE1 inhibition. Tehranolide significantly reduces cell proliferation in a time and dose-dependent manner in K562 cells which probably involves modulating cAMP/PKA signaling pathways via $\mathrm{CaM}$ and $\mathrm{PDE}$ inhibition. Thus, in short, tehranolide has a great potency as an antitumor agent.

\section{Conflicts of interest None}

Open Access This article is distributed under the terms of the Creative Commons Attribution License which permits any use, distribution, and reproduction in any medium, provided the original author(s) and the source are credited.

\section{References}

1. Mutiny M. Transcriptional regulation by cyclic AMP. Annu Rev Biochem. 1997;66:807-22.

2. Shabb JB. Physiological substrates of cAMP-dependent protein kinase. Chem Rev. 2001;101:2381-411.

3. Jacobs E, Bulpitt PC, Coutts IGC, Robertson JFR. New calmodulin antagonists inhibit in vitro growth of human breast cancer cell lines independent of their estrogen receptor status. Anticancer Drugs. 2000;11:63-8.

4. Montminy M. Transcriptional regulation by cyclic AMP. Annu Rev Biochem. 1997;66:807-22.

5. Victoria B, Domenico S, Clive P. Phosphodiesterase inhibitors. Br J Pharmacol. 2006;147:252-7.

6. Hirsh L, Dantes A, Suh BS, Yoshida Y. Phosphodiesterase inhibitors as anticancer drugs. Biochem Pharmacol. 2004;68:981-8.

7. Marika S, Ve'ronique M, Sylvie B, Manuel R. Sildenafil and vardenafil, types 5 and 6 phosphodiesterase inhibitors, induce caspase-dependent apoptosis of B-chronic lymphocytic leukemia cells. Blood. 2003;101:265-9.

8. Francis SH, Turko IV, Corbin JD. Cyclic nucleotide phosphodiesterases: relating structure and function. Prog Nucleic Acid Res Mol Biol. 2001;65:1-52.

9. Ahn EY, Pan G, Oh JH, Tytler EM, McDonald JM. The combination of calmodulin antagonists and interferon-gamma induces apoptosis 
through caspase-dependent and -independent pathways in cholangiocarcinoma cells. Am J Pathol. 2003;163:2053-63.

10. Xie B, Ling JJ. Anti-tumor activity of artemisinin and its derivatives. J Guangzhou Univ Tradit Chin Med. 2005;22:75-7.

11. Balint GA. Artemisinin and its derivatives, an important new class of antimalarial agents. Pharmacol Ther. 2001;90:261-5.

12. Nakase I, Lai H, Singh NP, Sasaki T. Anticancer properties of artemisinin derivatives and their targeted delivery by transferrin conjugation. Int J Pharm. 2008;354:28-33.

13. Singh NP, Lai HC. Artemisinin induces apoptosis in human cancer cells. Anticancer Res. 2004;24:2277-80.

14. Amy E, James L, Maggs B, Xiao-Ming S, Gerald M, Cohen J, et al. Evidence for the involvement of carbon-centered radicals in the induction of apoptotic cell death by artemisinin compounds. J Biol Chem. 2007;282:9372-82.

15. Efferth T, Benakis A, Romero MR. Enhancement of cytotoxicity of artemisinins toward cancer cells by ferrous iron. Free Radic Biol Med. 2005;37:998-1009.

16. Al-khathlan HZ, Mousa A, Al-Haziki. Sesquiterpene lactones from Artemisia species. Jour Chem Soc Pak. 1992;14:151-65.

17. Noori S, Naderi G, Hassan M, Habibi Z, Bathaie Z, Hashemi M. Immunosuppressive activity of a molecule isolated from Artemisia annua on DTH responses compared with cyclosporin A. Int Immunopharmacol. 2004;4:1301-6.

18. Noori S, Hassan Z, Rezaei B, Rustaiyan A, Habibi Z, Fallahian F. Artemisinin can inhibit the calmodulin-mediated activation of phosphodiesterase in comparison with cyclosporin A. Int Immunopharmacol. 2008;8:1744-7.

19. Noori S, Hassan Z, Taghikhani M, Rezaei B, Habibi Z. Dihydroartemisinin can inhibit calmodulin, calmodulin-dependent phosphodiesterase activity, and stimulate cellular immune responses. Int Immunopharmacol. 2010;10:213-7.

20. Noori S, Taghikhani M, Hassan Z, Al-lameh A. Tehranolide could shift the immune response towards Th1 and modulate the intra-tumor infiltrated $\mathrm{T}$ regulatory cells. Iran $\mathrm{J}$ Immunol. 2009;6:216-24.

21. Noori S, Taghikhani M, Hassan ZM, Allameha A, Mostafaei A. Tehranolide molecule modulates the immune response, reduce regulatory $\mathrm{T}$ cell, and inhibits tumor growth in vivo. Mol Immunol. 2010;47:1579-84.

22. Noori S, Hassan ZM. Tehranolide inhibits proliferation of MCF-7 human breast cancer cells by inducing G0/G1 arrest and apoptosis. Free Radic Biol Med. 2012;52:1987-99.

23. Pace CN. Measuring and increasing protein stability. TIB Tech. 1990;8:93-8.

24. Balshaw DM, Xu L, Yamaguchi N, Pasek DA, Meissner G. Calmodulin binding and inhibition of cardiac muscle calcium release channel (ryanodine receptor). J Biol Chem. 2001;276:2014453.

25. Wu X, Ahn EY, McKenna MA, Yeo H, McDonald JM. Fas binding to calmodulin regulates apoptosis in osteoclasts. J Biol Chem. 2005;280:29964-70.

26. Dewhurst LO, Gee JW, Rennie IG, MacNeil S. Tamoxifen, 17betaoestradiol, and the calmodulin antagonist J8 inhibit human melanoma cell invasion through fibronectin. Br J Cancer. 1997;75:860-8.

27. Maxwell CR, Kanes SJ, Abel T, Siegel SJ. Phosphodiesterase inhibitors: a novel mechanism for receptor-independent antipsychotic medications. Neuroscience. 2004;129:101-7.

28. Weiss B, Hait WN. Selective cyclic nucleotide phosphodiesterase inhibitors as potential therapeutic agents. Ann Rev Pharmacol Toxicol. 1977; 17:441-77.

29. Nam W, Tak J, Ryu JK. Effects of artemisinin and its derivatives on growth inhibition and apoptosis for all cancer cells. Head Neck. 2007;29:335-40.

30. Colm M, Byron G, Jeffrey W, Roman G, Funda V, David R, et al. Effect of artemisinin derivatives on apoptosis and cell cycle in prostate cancer cells. Anticancer Drugs. 2010;21:423-32. 